\title{
Tु SAFETY ISSUES WITH ELECTRIC VEHICLES
}

\author{
Yash Mathur ${ }^{1}$, Dr. Pushpendra Singh ${ }^{2}$, Yash Kumar Singh ${ }^{3}$ \\ mathuryash93@gmail.com¹,pushpendrasingh@jklu.edu.in ${ }^{2}$,yashkumarsingh2@outlook.com³ \\ Mechanical $^{1}$, Electrical ${ }^{2,3}$, Department, JK Lakshmipat University, Jaipur, India
}

Abstract- There is currently a trend towards energy green saving vehicles with electric power. This paper discuss some potential hazards associated with electric vehicles and the protection against electric shock to the person interacting with electric vehicles in light of the advancement of the technology. The safety of users may be challenged by the vehicle's increased operating voltages, at different frequencies, possibly making more complex the protection against direct and indirect contacts.

Keywords- Electrical Safety, Protection, Electric Vehicle, Battery.

\section{INTRODUCTION}

The constant growing fuel prices and increase in environmental pollution contribute to the continuous search for solutions for cleaner \& cheaper transportation. Therefore Electric vehicles (EV) are seen as a possible alternative because they have the potential to stand apart. However, they are very different from conventional vehicles. Clearly, electric vehicles are not inherently unsafe, nor will they necessarily expose the public to greater risks than internal combustion engine vehicles. Nevertheless, there is always the risk for unintended consequences whenever a new technology comes into play.

\section{ELECTRIC VEHICLE}

An electric vehicle (EV) is also referred to as an electric drive vehicle, is a vehicle which uses one or more electric motors for propulsion. Electric vehicles includes electric cars, electric trucks, electric lorries, electric trains, electric boats, electric motorcycles and scooters, and electric spacecrafts also.

An electric automobile is another automobile that uses electric motors and power controllers for propulsion, instead of very common propulsion methods such as the internal combustion engines (ICE). Electricity can be used as a transportation fuel to power battery electric vehicles (BEVs). EVs store electricity in an energy storage devices, such as a battery, fuel cell, super capacitor etc. The electricity powers the vehicle's wheels through an electric motor. EVs have limited energy storage capacity, which must be replenished by plugging into an electrical source. [2]

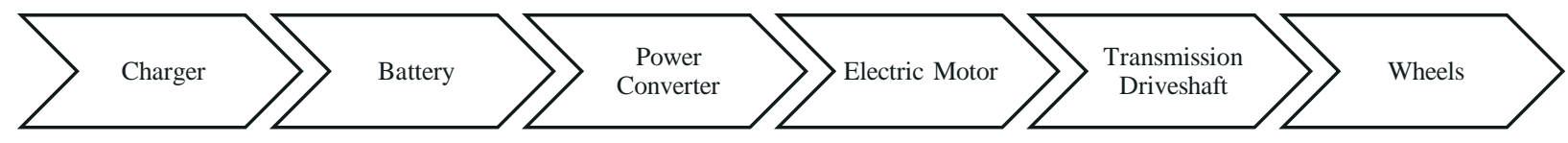

Fig. 3.1 Block Diagram of Electric Vehicle

Electric vehicles are different from conventional fossil fuel-powered vehicles as they can receive their power from a wide range of sources including nuclear power, fossil fuels and renewable sources such as geothermal, tidal, solar and wind power or any combination of these. Whatever the way it is generated, this energy is then transmitted to the vehicle through use of overhead lines, wireless energy transfer such as inductive charging, or a direct connection through an electrical cable.

Vehicles making use of engines working on the principle of combustion can usually only derive their energy from a single or a few sources, usually non-renewable fossil fuels. A key advantage of electric vehicles is their ability to recover braking energy as electricity to be restored to the on-board battery (regenerative braking) or sent back to the grid (V2G). [6]

\section{EV SAFETY ISSUES \& POSSIBLE SOLUTIONS}

There are various aspects of electrical safety in electric vehicles. They are -

$>$ Safety of the electrical system

$>$ Safety in the functioning of system

$>$ Safety while dealing with batteries

$>$ Maintenance and operation of the vehicle. [3]

\subsection{Safety of Electrical System}

The protection against electric shocks encompasses levels of voltage in electric vehicles \& protection against direct $\&$ indirect contact. The protection against direct contact is carried out by the sufficient insulation of live parts within 


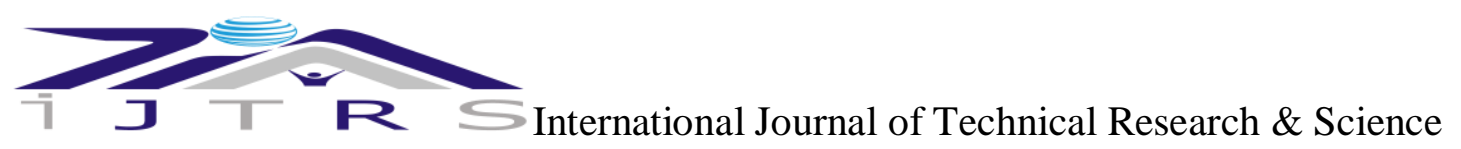

the Electric Vehicle, such as insulated wires and enclosures; insulation must be removable only by destruction and commensurate with the operating voltage of the system. An electric vehicle that is not under charging, is an electrical system whose source is isolated from ground. As a result, the touch with a live part will not cause the circulation of harmful currents through the person. However, the degradation of the insulation of live parts, which are simultaneously accessible, exposes persons to electric shock, as the EV operating voltages may exceed the limit of voltage conventionally assumed as safe for human that is $30 \mathrm{~V} \mathrm{AC}$ and $40 \mathrm{~V} \mathrm{DC}$. The EV chassis conductive structure can be used to detect loss of isolation \& automatically disconnect the source(s) from the power train, or the rest of the power train, when the EV is in non-motoring mode (e.g., ignition off, EV in parking, etc.).

The risk of electric shock increases if the negative terminal of the battery is connected to the chassis of the vehicle, which is the conductive structure of the EV, not energized during normal vehicle operation. In this case, in fact, due to the large conductive surface of the EV, the probability that the person, already in contact with a part at the positive terminal potential, will also be in contact with the chassis is higher. In the presence of the connection between the battery negative terminal and the chassis, the probability that the chassis will be temporarily and unintentionally connected to ground, for instance due to the contact of the car jack when changing a tire, or due to a person touching under the hood for repairs, increases. In these conditions, the source is no longer isolated from ground, and the one-terminal contact becomes equally dangerous as the two-terminal contact.

\subsection{Safety Regarding the Functioning of the Systems}

The driving system of the EV must ensure reliable and safe operation of the vehicle. An electric vehicle is fundamentally different from vehicles with internal combustion engine and therefore certain measures should be taken to prevent unsafe operation. When the electric vehicle stands in situ it's completely silent. To prevent unwanted movement through activation of the drive circuit there must be a warning system. Procedure access must be properly organized in order to avoid possible harm through excessive torque, amperage or acceleration, which means that it should be impossible to activate the controller when the accelerator is pressed. For electric vehicles it is mandatory to have presence of an emergency stop switch. Electromagnetic interference coming from outside or from the controller must not affect it's functioning.

Auxiliary power supplies are used for Air Conditioning, lighting, wipers of the windscreen and other similar burdens. It is powered by the main drive battery through the DC - DC converter even though in most vehicles there's auxiliary battery. Regardless of the power supply to the drive the job of additional consumers (especially lights) must be assured in all conditions.

When it comes to regenerative braking, there should be some security references. Regenerative braking solely operates through the transmission shaft and operates at very low speeds or at a standstill. In some cases the level of deceleration is not sufficient for immediate braking. The effect of regeneration braking can be reduced once the battery is fully charged. For these reasons primary friction braking system ought to be able to stop the vehicle beneath any circumstances.

\subsection{Battery Safety}

The most critical \& important part for any electric vehicle is battery. It presents various potential hazards: electrical, mechanical, chemical and danger of explosion. The electrical aspects include protection against electric shock and short circuit for instance, fuses and circuit breakers that disconnect the batteries when the collision detectors \& sensors become aware that the battery pack is on the point to sustain damage. When using multiple batteries it should provide standard locking connections. Also the battery housing must be designed so that it will avoid unintentional direct contact or short circuit.

When talking about the mechanical aspects, since the battery is heavy part of its position it should be determined as to avoid instability of the vehicle and it should be limited to avoid damage in case of accident.

The dangers from chemical aspect depend upon the battery type. During the process of charging the battery, electric vehicle is connected to the main distribution network and should take all precautions to avoid risk of electric shock. They should consider several cases. "Off-board" battery chargers are generally used for big vehicles and for quick charging. With these chargers it's essential to earth the vehicle while it's is full, because it can lead to danger in case of emergency. With "on-board" battery chargers the vehicle should be connected to the ground during the charging, except when used equipment is Class II (double insulation). It is recommended to check the correctness of earthing through a control device for earthing. When the charger doesn't have electrical division monitoring is necessary of the drive battery isolation and must be isolated from the vehicle body. [5]

\subsection{Maintenance \& Training}

Because of their differing technologies, electric vehicles have different types of minimal scheduled maintenance to their electrical systems, which can include the battery, electrical motor, and associated electronics. However, because of regenerative braking, brake systems on EVs typically last longer than on conventional vehicles.

DOI Number: https://doi.org/10.30780/IJTRS.V04.I09.001

$$
\begin{aligned}
& \text { www.ijtrs.com } \\
& \text { www.ijtrs.org }
\end{aligned}
$$




\section{TR SInternational Journal of Technical Research \& Science}

Since an ordinary consumer is not a trained electrician and must therefore be protected against all risks of direct contact.

The second row within the maintenance are the workshops. Employees at workshop must be thoroughly trained in the safe maintenance actions in servicing of electric vehicles. The battery ought to be disconnected before any intervention.

Third row is holding workshops, manufacturer and include the main electrical repairs. This should be done only by trained personnel. Besides maintenance of mechanical elements it's necessary to possess electrical and routine maintenance for safe operation. These includes testing the resistance of insulation and earth leakage functioning controller, battery status as well as its maintenance and cleaning.

The electric car is not similar to conventional fuel operated vehicles. The electric motor has the characteristics of torque and power that are totally different from the internal combustion engines. Safe and energy efficient electric driving vehicle requires appropriate and acceptable skills.

\section{RECOMMENDATION}

For electric vehicles there's no space for everyday driving style as it is with conventional powered vehicles. Especially the charging should be done properly and with the required discipline. Therefore users of electric vehicles must be equipped with the required information or user manuals from the responsible authorities, seller or manufacturer.

Every day, the market introduces new types of batteries \& electrical drives, therefore the laboratories security practice will need to develop. Current procedures for safety of electric or hybrid vehicles are a good starting point for developing new ones. [4]

\section{CONCLUSION}

Since the use of Electric Vehicles will be encouraged in order to protect the environment and conventional fuels, they are the future of transport system. It is also required that people must be ready to take newer risks that will come with the entirely new technology.

New driving practices and road safety measures such as the habits and rules of participation in traffic, storage, charging, maintenance and procedure in case of an emergency are some of the prime requirements to welcome the new era of transport.

Electric vehicles can become safe and reliable way of transport which will improve traffic and the impact on the environment in the future. Although the full use of this type of vehicles will enter later in our country but we should be prepared to support the vehicles that will be passing through the country.

\section{ACKNOWLEDGEMENT}

This research was supported by JK Lakshmipat University, Jaipur. I thank my guide who provided insight, expertise and comments that greatly assisted the research and improved the manuscript.

I would also like to show my gratitude to the Dr. Sanjay Goel, Director, IET, JK Lakshmipat University for sharing his pearls of wisdom during the course of this research. Although any errors are of my own and should not tarnish the reputations of this institute and the esteemed person.

\section{REFERENCES}

[1] "Guidelines for Electric Vehicle Safety", SAE International J2344, 2010

[2] Visvikis, Costandinos. (2012). Safety considerations for electric vehicles and regulatory activities. 26th Electric Vehicle Symposium 2012, EVS 2012. 2.

[3] Van den Bossche, Peter. "Safety considerations for electric vehicles." International Electric Vehicle Symposium, and Norman Bryan. 1994. Symposium proceedings, the 12th International Electric Vehicle Symposium (EVS-12) and Electric Vehicle Exposition. San Francisco, CA: EVAA.

[4] Christopher Lampton "Are electric cars safe in accidents?" 6 December 2011.HowStuffWorks.com. https://auto.howstuffworks.com/are-electric-cars-safe-in-accidents.htm 22 March 2019

[5] Viladot, A., Palsson, I., Jonsson, H. and Torstensson, H. (1999). "Risk in connection with electric vehicles." Gothenburg, Sweden: SSPA Sweden AB.

[6] Larminie, J., \& Lowry, J. (2004). Electric Vehicle Technology Explained (1st ed., pp. 1 - 29). Chichester: Wiley. 